\title{
Analisis Senyawa Toksik Tepung Pelepah Batang Aren (Arenga pinnata) dengan Spelktroskopi UV-Vis dan Inframerah
}

\author{
Irma Dukomalamo a, Meiske Sientje Sangi a*, Johnly Alfreds Rorong a \\ aJurusan Kimia, FMIPA, Unsrat, Manado
}

KATA KUNCI

Arenga pinnata L.

Artemia salina L.

toxicity

\begin{abstract}
A B S T R A K
Telah dilakukan penelitian mengenai analisis senyawa toksik tepung pelepah batang aren ( $A$. pinnata) dengan spektroskopi UV-Vis dan inframerah dengan tujuan untuk mengisolasi senyawa toksik dari tepung pelepah batang aren dan menganalisis senyawa toksik tersebut dengan spektroskopi UV-Vis dan inframerah. Tepung pelepah batang aren diekstraksi dengan cara maserasi menggunakan pelarut etanol hasil redestilasi cap tikus. Ekstrak diuji dengan Kromatografi Lapis Tipis (KLT) untuk menentukan jenis eluen terbaik untuk dipisahkan dengan kromatografi kolom sehingga diperoleh fraksi-fraksi. Fraksi hasil kromatografi kolom diuji KLT ulang, noda sama dari beberapa fraksi digabungkan. Fraksi yang hanya memiliki 1 noda dilakukan uji toksisitas dengan metode Brine Shrimp Lethality Test (BSLT) menggunakan larva udang Artemia salina L. dan dianalisis menggunakan spektroskopi UV-Vis dan inframerah. Hasil pengujian KLT diperoleh 6 noda dengan nilai $R f$ yaitu noda (a) 0,961; (b) 0,857; (c) 0,779; (d) 0,714; (e) 0,623; (f) 0,376. Fraksi A hasil kromatografi kolom dengan noda tunggal yang dilakukan uji $\mathrm{KLT} R f=0,961$. Fraksi A yang diuji toksisitas menunjukkan fraksi bersifat toksik dengan nilai LC50 sebesar 269,15 ppm. Analisis spektrofotometer UV-Vis dan Inframerah menunjukkan bahwa fraksi memiliki gugus fungsi $\mathrm{C}=\mathrm{O}$, $-\mathrm{C}-\mathrm{O}$ ester, $-\mathrm{C}=\mathrm{C}$ alkena, serta $\mathrm{C}-\mathrm{C}$ dan $\mathrm{C}-\mathrm{H}$ alkana. Dari hasil penelitian dapat disimpulkan bahwa senyawa yang diisolasi dari tepung pelepah batang aren bersifat toksik dengan nilai LC50 sebesar 269,15 ppm dan merupakan senyawa nonpolar yang memiliki gugus fungsi $-\mathrm{C}=0$, -C-O ester, $-\mathrm{C}=\mathrm{C}$ alkena, serta $\mathrm{C}-\mathrm{C}$ dan $\mathrm{C}-\mathrm{H}$ alkana.
\end{abstract}

KEYWOR DS

Arenga pinnata $\mathrm{L}$. Artemia salina L. toxicity

\begin{abstract}
A B S T R A C T
A research has been done about Analysis of Toxic Compounds Sugar Palm Stem Midrib Flour (A. Pinnata) using UV-Vis and Infrared Spectroscopy, aimed to isolated of toxic compounds sugar palm stem midrib flour and analyze using UV-Vis and infrared spectroscopy. Sugar palm stem midrib flour extracted by maceration using ethanol as solvent results from redistillation cap tikus. The extract was tested by Thin Layer Chromatography (TLC) to determine the best eluent for separated with column chromatography to obtained fractions. Fractions column chromatography results were tested using $\mathrm{KLT}$, the same spot of fractions were combined. Fraction having 1 spot was toxicity test performed by the method of Brine Shrimp Lethality Test (BSLT) using Artemia salina L. larvae and analyze using UV-Vis and infrared spectroscopy. Results KLT testing obtained six spots with $R f$ is (a) 0,961 ; (b) 0,857 ; (c) 0,779 ; (d) 0,714 ; (e) 0,623 ; (f) 0,376 . Fraction A column chromatography results having one spot by KLT test with $R f=0,961$. The results of toxicity test
\end{abstract}


showed fraction A was toxic with LC50 $_{50} 269,15$ ppm. Analysis spectrophotometer UV-Vis and inframerah showed that fraction had functional group like $-\mathrm{C}=\mathrm{O},-\mathrm{C}-\mathrm{O}$ esther, $-\mathrm{C}=\mathrm{C}$ alkene, $\mathrm{C}-\mathrm{C}$ and $\mathrm{C}-\mathrm{H}$ alkane. This research concludes compound of sugar palm stem midrib flour isolated sugar palm stem midrib flour and nonpolar compound with functional group like $-\mathrm{C}=\mathrm{O},-\mathrm{C}-\mathrm{O}$ esther, $-\mathrm{C}=\mathrm{C}$ alkene, $\mathrm{C}-\mathrm{C}$ and $\mathrm{C}-\mathrm{H}$ alkane.

TERSEDIA ONLINE

29 Maret 2016

\section{Pendahuluan}

Tanaman aren (Arenga pinnata) merupakan salah satu jenis sumber daya alam yang banyak terdapat di Indonesia, khususnya daerah tropis seperti Sulawesi Utara. Tanaman aren merupakan salah satu jenis tanaman pinang-pinangan yang serbaguna. Masyarakat Sulawesi Utara mengenal tanaman aren sebagai tanaman yang hampir seluruh bagian tanamannya dapat dimanfaatkan, mulai dari akar hingga daun. Menurut Sangi et al. (2012) tepung dari pelepah batang aren mengandung senyawa fitokimia diantaranya alkaloid, tannin, dan triterpenoid. Selain itu, Mokoginta (2014) menyatakan bahwa pelepah batang aren mengandung senyawa saponin, steroid, fenolik dan memiliki potensi sebagai antioksidan.

Selain mengandung senyawa fitokima, tepung pelepah batang aren juga bersifat toksik (Sangi et al., 2012). Suatu komponen dalam ekstrak tanaman tertentu dikatakan toksik apabila dapat menyebabkan kematian pada larva udang dengan nilai $\mathrm{LC}_{50}>1000 \mu \mathrm{g} / \mathrm{ml}$ yang dilakukan dengan metode Brine Srimp Letality Test (BSLT). Sehingga, perlu dilakukan penelitian lebih lanjut mengenai isolasi senyawa toksik dari tepung pelepah batang aren yang diduga dapat dijadikan sebagai obat luka bakar dan gatal-gatal pada kulit serta menganalisis karakteristik dari senyawa toksik tersebut dengan spektrofotometer UV-Vis dan Inframerah.

\section{Material dan Metode}

Bahan yang digunakan dalam penelitian ini adalah tepung yang diperoleh dari bagian dalam pelepah batang aren yang telah tua yang diambil di daerah Ratahan, Minahasa Tenggara, telur Artemia salina Leach, dan garam bubuk non-komersial. Bahan kimia yang akan digunakan adalah etanol (teknis dan p.a), heksana (p.a), etil asetat (p.a), 2butanol (p.a), silica gel G 60 dan air. Alat yang digunakan adalah seperangkat alat gelas, kertas saring, alat rotary evaporator, beaker gelas, thermometer, statif, hot plate, corong, gelas ukur, tabung raksi, corong pisah, botol vial, satu set alat kromatografi lapis tipis, satu set alat kromatografi kolom, lampu UV, spektrofotometer UV-Vis 1800 Simadzu, serta spektrofotometer inframerah FTIR Prestige-21 Simadzu.

\subsection{Preparasi Sampel}

Pelepah batang aren yang telah tua yang diambil dari hutan dibersihkan dan diambil bagian dalamnya. Bagian dalam pelepah batang aren berupa tepung yang berwarna abu-abu diambil dan diayak sehingga bersih dari pengotor. Selanjutnya tepung yang diperoleh disimpan dalam wadah yang tertutup untuk dilakukan analisa lebih lanjut.

\subsection{Ekstraksi Sampel}

Sebanyak $600 \mathrm{~g}$ tepung pelepah batang aren diekstraksi dengan cara maserasi menggunakan pelarut etanol yang diperoleh dari redestilasi cap tikus. Perendaman dilakukan selama 24 jam pada suhu kamar, disaring dengan menggunakan kertas saring untuk diperoleh ekstrak. Selanjutnya filtrat yang dihasilkan disimpan dalam wadah tertutup, sedangkan ampas yang diperoleh diekstraksi lagi dengan pelarut yang sama hingga diperoleh filtrat yang tidak berwarna.

Filtrat hasil ekstraksi digabungkan dan di diuapkan dengan rotary vacuum evaporator sehingga diperoleh ekstrak kental etanol. Selanjutnya ekstrak kental tersebut dianalisis dengan kromatografi lapis tipis untuk menentukan jenis eluen terbaik untuk pemisahan dengan kromatografi kolom.

\subsection{Isolasi dan Pemurnian Senyawa}

\subsubsection{Pengujian dengan Kromatografi Lapis Tipis (Modifikasi Mahmudah, 2014)}

Ekstrak n-heksana yang dihasilkan dari ekstraksi dilakukan pemisahan dengan menggunakan kromatografi kolom. Sebelum analisis dengan kromatografi kolom, dilakukan analisis dengan KLT untuk menentukan jenis pelarut yang digunakan. Selanjutnya ekstrak etanol dianalisis KLT dengan campuran $\mathrm{n}$-heksana dan etil asetat dengan berbagai perbandingan (8:2; 7:3; 7,5:2,5; 6:4). Setelah totolan kering, plat KLT diamati secara visual dengan menggunakan lampu UV agar dapat dilihat noda pemisahan. Eluen dari fraksi yang memiliki noda pemisahan yang paling baik akan dijadikan sebagai fase gerak pada pemisahan dengan kromatografi kolom. Senyawa yang dihasilkan dari KLT dapat dianalisis menghitung nilai $R f$ (Retardation factor) yang didefenisikan sebagai berikut:

$$
R f=\frac{\text { Iarak komponen yang bergerak }}{\text { Iarak pelarit yang bergerak }}
$$




\subsubsection{Pemisahan dengan Kromatografi Kolom}

Pemisahan yang dilakukan dengan kromatografi kolom menggunakan fase gerak yang dihasilkan dari pengujian dengan KLT yaitu perbandingan 7,5:2,5 (nheksana:etil asetat) sedangkan fase diam silica gel $\mathrm{G}$ 60. Silica gel sebanyak $100 \mathrm{~g}$ terlebih dahulu dibuat menjadi bubur dengan eluen yang akan digunakan, dan dimasukkan ke dalam kolom dengan hati-hati. Sebelum silica dimasukkan kolom terlebih dahulu diisi dengan eluen hingga batas tertentu.

Selanjutnya tahap pengaplikasian sampel, sebanyak 2 g ekstrak etanol dari tepung pelepah batang aren yang telah dilarutkan dengan eluen dimasukkan ke dalam kolom secara perlahan. Ekstrak yang telah masuk ditambahkan eluen dengan kran kolom dalam keadaan terbuka. Untuk menjaga agar kolom tidak rusak, eluen harus selalu ditambahkan. Pelarut yang keluar dari kolom ditampung dalam botolbotol vial yang diberi nomor. Tiap-tiap fraksi yang dihasilkan ditampung sebanyak $5 \mathrm{~mL}$. Masing-masing botol fraksi dilakukan uji KLT kembali, pola pemisahan sama dari beberapa fraksi digabungkan. Gabungan fraksi yang hanya memiliki 1 noda dijadikan sebagai fraksi murni yang akan dilakukan uji toksisitas dan dianalisis menggunakan spektrofotometer UV-Vis dan Infra Merah.

\subsection{Uji Toksisitas Menggunakan Larva A. salina Leach}

\subsubsection{Penyiapan Larva A. salina Leach}

Uji toksisitas menggunakan larva udang Artemia salina dilakukan menurut metode Meyer et al. (1982). Mula-mula larva udang disiapkan dengan cara menetaskan telur $A$. salina Leach selama dua hari sebelum dilakukan pengujian. Penetasan dilakukan dengan cara merendam telur udang tersebut ke dalam gelas piala $2000 \mathrm{~mL}$ yang berisi air laut buatan. Air laut buatan dibuat dengan melarutkan $40 \mathrm{~g}$ garam bubuk non-komersial ke dalam $2 \mathrm{~L}$ air kran, disaring dan diaerasi. Setelah 48 jam perendaman, telur menetas dan menghasilkan larva $A$. salina Leach yang siap digunakan dalam pengujian.

\subsubsection{Penyiapan Sampel}

Sebanyak 0,01 g sampel, dilarutkan dengan 10 $\mathrm{mL}$ air laut buatan untuk membuat larutan uji dengan konsentrasi 1000 ppm. Dari larutan uji 1000 ppm, selanjutnya dibuat lagi larutan dengan konsentrasi 500, 250 dan 100 ppm dengan cara pengenceran. Untuk kontrol dilakukan tanpa penambahan ekstrak.

\subsubsection{Uji Toksisitas}

Larutan uji dengan konsentrasi dipipet sebanyak $5 \mathrm{~mL}$ dimasukkan ke dalam tabung reaksi dan ditambahkan 10 ekor larva udang yang telah berumur 2 hari. Dilakukan dua kali pengulangan dan dibandingkan dengan kontrol. Pengamatan dilakukan selama 24 jam dengan selang waktu 1 jam untuk menghitung jumlah larva yang mati.

\subsection{Analisis Fraksi}

Senyawa murni yang telah diperoleh kemudian dianalisis dengan spektrofotometer UV-Vis pada panjang gelombang 220-500 nm dan Spektrofotometer Inframerah untuk mengidentifikasi kandungan dari senyawa tersebut.

\section{Hasil dan Pembahasan}

\subsection{Ekstraksi}

Ekstrak etanol tepung pelepah batang aren sebelumnya telah dilakukan uji toksisitas dengan harga LC50 yang diperoleh 6,295 ppm dan skrining fitokimia yang menunjukkan adanya senyawa alkaloid, triterpenoid dan tannin (Sangi et al., 2012). Tepung pelepah batang aren sebanyak $600 \mathrm{~g}$ diekstraksi dengan cara maserasi menggunakan pelarut etanol hasil redestilasi cap tikus menghasilkan ekstrak dan hasil rendemen yang dapat dilihat pada Tabel 1.

Tabel 1. Rendemen ekstrak etanol tepung pelepah batang aren.

\begin{tabular}{|c|c|c|}
\hline \multicolumn{2}{|c|}{ Massa (g) } & \multirow{2}{*}{$\begin{array}{c}\text { Rendemen } \\
\text { (\%) }\end{array}$} \\
\hline Sampel serbuk & Ekstrak & 1,3 \\
\hline 600 & 7,8 & 1,3 \\
\hline
\end{tabular}

Nilai rendemen yang kecil kemungkinan disebabkan oleh ukuran partikel dari tepung pelepah batang aren saat maserasi tidak seragam sehingga proses ekstraksi kurang sempurna dan senyawa yang terekstraksi menjadi lebih sedikit. Selain itu, senyawa yang larut dalam pelarut etanol yang bersifat polar hanya sedikit sehingga ekstrak yang hasilkan dalam jumlah kecil. Silva et al. (1998) melaporkan bahwa suatu ekstrak tamanan jika dimaserasi akan menghasilkan perbedaan tekanan antara dalam dan luar sel ekstrak, yang menyebabkan senyawa-senyawa dalam sel akan larut dalam pelarut yang sesuai.

\subsection{Isolasi dan Pemurnian Senyawa}

Setelah diperoleh ekstrak etanol tepung pelepah batang aren, selanjutnya dilakukan isolasi dan pemurnian senyawa yang terkandung dalam ekstrak kental tersebut. Isolasi dan pemurnian senyawa pada umumnya dilakukan untuk mengisolasi atau memisahkan jenis-jenis senyawa yang terkandung dalam ekstrak tanaman tertentu. Tahap ini dilakukan dengan analisis kromatografi lapis tipis (KLT) dan kromatografi kolom.

\subsection{Kromatografi Lapis Tipis}

Ekstrak etanol tepung pelepah batang aren yang diperoleh dilakukan pengujian pendahuluan dengan KLT untuk menentukan jenis eluen terbaik yang akan digunakan pada pemisahan dengan kromatografi kolom. Pengujian dengan KLT merupakan salah satu teknik kromatografi termudah dan tercepat, selain itu pengujian ini pada dasarnya digunakan untuk uji pendahuluan untuk melihat pola pemisahan dari ekstrak pada jenis eluen tertentu. 
Pada pengujian KLT pendahuluan, fase diam yang digunakan adalah plat silica dan fase gerak adalah perbandingan pelarut $n$-heksana dan etil asetat (7,5:2,5). Dari hasil KLT menunjukkan terjadinya pemisahan dengan adanya beberapa pola yang dilihat dibawah lampu UV. Spot yang dihasilkan sebanyak 6 spot yang menunjukkan adanya 6 senyawa pada ekstrak etanol pelepah batang aren yang akan dipisahkan dengan kromatografi kolom.

\subsection{Kromatografi Kolom}

Pemisahan senyawa dari ekstrak kental etanol sebanyak 2 g dilakukan menggunakan kromatografi kolom, sebagai fase gerak yang digunakan adalah perbandingan $n$-heksana : etil asetat $(7,5: 2,5)$ yang digunakan pada KLT dan fase diam silica gel 60 sebanyak 100 g. Dari hasil pemisahan dengan kromatografi kolom diperoleh fraksi sebanyak 18 vial. Masing-masing fraksi tersebut di-KLT untuk melihat pola pemisahannya.

Berdasarkan hasil KLT fraksi yang memiliki pola noda yang sama adalah fraksi no. 3-5 dijadikan fraksi A, fraksi no. 6-7 menjadi fraksi $B$, dan fraksi no. 8-9 menjadi fraksi C.Dari masing-masing fraksi (A-C), fraksi
A yang memiliki pola noda tunggal yang artinya hanya terdapat satu senyawa dalam fraksi tersebut.

Dari hasil KLT dapat dikatakan bahwa fraksi hasil isolasi ekstrak etanol tepung pelepah batang aren merupakan fraksi yang sudah murni karena pada plat KLT hanya terdapat 1 noda yang dideteksi dengan eluen n-heksana : etil asetat dengan nilai $R f 0,961$. Pada penelitian ini fraksi yang diperoleh dalam jumlah yang sedikit sehingga uji kemurnian hanya dilakukan dengan 1 eluen. Pada fraksi A didapatkan nilai $R f$ lebih besar dari fraksi-fraksi lain, hal ini menunjukkan fraksi tersebut merupakan senyawa nonpolar, sehingga proses elusi pada plat KLT lebih cepat. Selanjutnya, fraksi yang telah murni tersebut dapat dianalisis lebih lanjut dengan spektrofotometer UV-Vis dan Inframerah, serta diuji toksisitas.

\subsection{Uji Toksisitas Fraksi A}

Uji toksisitas pada fraksi A dari kromatografi kolom ekstrak tepung pelepah batang aren dilakukan dengan konsentrasi 500, 250, dan 100 ppm pada larva Artemia yang telah berumur 2 hari, dengan perlakuan duplo. Kematian larva dilihat dengan selang waktu 1 jam selama 24 jam perlakuan. Hasil analisis untuk uji toksisitas fraksi $A$ dapat dilihat pada Tabel 2.

Tabel 2. Hasil Uji Toksisitas Fraksi A Hasil Isolasi Ekstrak Etanol Tepung Pelepah Batang Aren terhadap Artemia salina

\begin{tabular}{|c|c|c|c|c|c|c|}
\hline \multirow[t]{2}{*}{ No. } & \multirow{2}{*}{$\begin{array}{l}\text { Konsentrasi } \\
(\mathrm{ppm})\end{array}$} & \multicolumn{2}{|c|}{ Ulangan } & \multirow[t]{2}{*}{ Rata-rata } & \multirow[t]{2}{*}{$\%$ Kematian } & \multirow[t]{2}{*}{$\mathrm{LC}_{50}$} \\
\hline & & 1 & 2 & & & \\
\hline 1 & 500 & 6 & 6 & 6 & 60 & \\
\hline 2 & 250 & 4 & 5 & 4,5 & 45 & \\
\hline 3 & 100 & 3 & 4 & 3,5 & 35 & 269,15 \\
\hline 4 & 0 & 0 & 0 & 0 & 0 & \\
\hline
\end{tabular}

Berdasarkan hasil yang diperoleh pada Tabel 2, semakin tinggi konsentrasi dari fraksi yang diuji kematian dari larva udang semakin besar. Dari hasil \%kematian larva dihitung \%kematian terkoreksi dan kemudian dikonversi ke nilai probit untuk menghitung harga LC50. Harga LC50 yang diperoleh dari fraksi terhadap larva A. salina sebesar 269,15. Menurut Meyer et al. (1982), suatu zat dikatakan toksik apabila harga $\mathrm{LC}_{50}<1000 \mu \mathrm{g} / \mathrm{mL}$, sehingga fraksi A dapat dikatakan bersifat toksik. McLaughlin et al. (1991) melaporkan bahwa suatu ekstrak dengan nilai $\mathrm{LC}_{50}<30 \mathrm{\mu g} / \mathrm{mL}$ ekstrak tersebut bersifat sitotoksik, LC $50 \geq 30-200 \mu \mathrm{g} / \mathrm{mL}$ berpotensi sebagai antibakteri, sedangkan LC50 $\geq 200-1000$ $\mu \mathrm{g} / \mathrm{mL}$ berpotensi sebagai pestisida. Berdasarkan pernyataan diatas dapat disimpulkan bahwa, fraksi A merupakan senyawa toksik yang berpotensi sebagai pestisida karena memiliki nilai LC50 lebih dari $200 \mu \mathrm{g} / \mathrm{mL}$.

\subsection{Analisis Fraksi}

\subsubsection{Analisis dengan Spektrofotometer Inframerah}

Hasil spektrum Inframerah dari senyawa fraksi A dengan spektrofometer Inframerah ditunjukkan pada Gambar 1 dengan serapan panjang gelombang dari fraksi ditunjukkan pada Tabel 3.

Berdasarkan dari hasil spektrum inframerah fraksi tepung pelepah batang aren yang terdapat pada gambar 4 dan tabel 3, dapat diinterpretasikan bahwa muncul serapan ulur $\mathrm{C}-\mathrm{H}$ alkena dengan intensitas sedang dan tajam pada daerah bilangan gelombang $3083,34 \mathrm{~cm}^{-1}, 3061,16 \mathrm{~cm}^{-1}$, dan 3031,26 $\mathrm{cm}^{-1}$ (Roberts, 1977), yang diperkuat dengan munculnya gugus $\mathrm{C}=\mathrm{C}$ alkena pada bilangan gelombang $1651,14 \mathrm{~cm}^{-1}$ yang biasanya muncul pada daerah serapan $1650 \mathrm{~cm}^{-1}$ (Smith, 2006). Vibrasi C-H alkana ditunjukkan pada bilangan gelombang 2927,10 $\mathrm{cm}^{-1}$, dan 2852,84 $\mathrm{cm}^{-1}$ dengan intensitas kuat dan tajam yang diperkuat dengan adanya serapan pada 1495,86 $\mathrm{cm}^{-1}$, $1451,50 \mathrm{~cm}^{-1}$ dan $1373,38 \mathrm{~cm}^{-1}$ yang menunjukkan adanya vibrasi bengkok $\mathrm{C}-\mathrm{H}$ yang berasal dari gugus 
$\mathrm{CH}_{3}-\mathrm{CH}_{2}$ yang biasanya muncul pada serapan bilangan gelombang 1495-1300 cm-1 (Sastrohamidjojo, 1997). Menurut Ridhia et al. (2013) dan Astuti et al. (2014), serapan yang muncul pada daerah sekitar $1372 \mathrm{~cm}^{-1}$ dan 1377 $\mathrm{cm}^{-1}$ menunjukkan adanya gugus $\mathrm{C}-\mathrm{H}$. Selain itu, serapan untuk vibrasi $\mathrm{C}-\mathrm{C}$ alkana juga muncul pada daerah sidik jari yaitu 758,06 $\mathrm{cm}^{-1}$ yang biasanya muncul pada daerah sekitar $1200-750 \mathrm{~cm}^{-1}$ (Roberts, 1977).

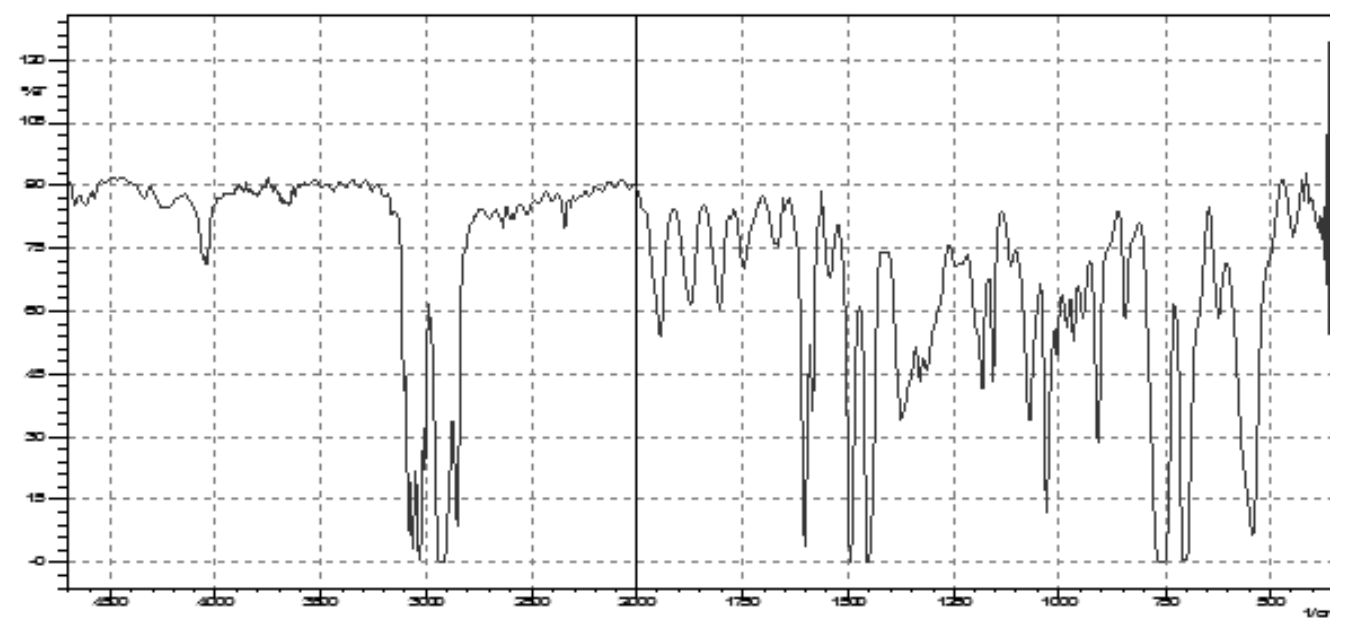

Gambar 1. Hasil Spektrum Inframerah Fraksi A

Tabel 3. Interpretasi Data Inframerah Fraksi A

\begin{tabular}{|c|c|c|c|c|c|}
\hline \multirow[t]{2}{*}{ No. } & \multicolumn{2}{|c|}{ Bilangan Gelombang $\left(\mathrm{cm}^{-1}\right)$} & \multirow[t]{2}{*}{ Intensitas } & \multirow[t]{2}{*}{ Bentuk Pita } & \multirow{2}{*}{$\begin{array}{l}\text { Kemungkinan Gugus } \\
\text { Fungsi }\end{array}$} \\
\hline & Pada Spektra & Pada Pustaka & & & \\
\hline 1 & $\begin{array}{l}3083,34 \\
3061,16 \\
3031,26\end{array}$ & 3100-3000\# & Sedang & Tajam & Ulur C-H Alkena \\
\hline 2 & $\begin{array}{l}2927,10 \\
2852,84\end{array}$ & $2960-2870 *$ & Kuat & Tajam & Ulur C-H Alkana \\
\hline 3 & 1651,14 & $1650 "$ & Sedang & Tajam & Ulur $\mathrm{C}=\mathrm{C}$ \\
\hline 4 & 1603,88 & $1820-1600 *$ & Kuat & Tajam & Ulur $\mathrm{C}=0$ \\
\hline 5 & $\begin{array}{l}1495,86 \\
1451,50 \\
1373,38\end{array}$ & $1495-1300 *$ & Kuat & Tajam & Bengkok $\mathrm{CH}_{3}, \mathrm{CH}_{2}$ \\
\hline 6 & 1069,57 & 1300-1035" & Kuat & Tajam & Ulur C-O ester \\
\hline 7 & 758,06 & 1200-750\# & Kuat & Lebar & C-C alkana \\
\hline
\end{tabular}

Serapan pada $1603,88 \mathrm{~cm}^{-1}$ menunjukkan adanya gugus $\mathrm{C}=\mathrm{O}$ yang diperkuat dengan adanya serapan yang menunjukkan adanya virbrasi ulur C-O ester pada bilangan gelombang 1069,57 cm-1 dengan intensitas kuat dan tajam yang biasanya muncul pada bilangan gelombang diantara 1300$1035 \mathrm{~cm}^{-1}$ (Roberts, 1977). Berdasarkan penelitian Rumondang et al. (2013), serapan yang muncul pada $1736,63 \mathrm{~cm}^{-1}$ menunjukkan adanya gugus $\mathrm{C}=\mathrm{O}$ ester alifatik jenuh, dan vibrasi ulur $\mathrm{C}-\mathrm{O}$ ester pada bilangan gelombang diantara $1000-1320 \mathrm{~cm}^{-1}$.

\subsubsection{Spektrofotometer UV-Vis}

Hasil analisis fraksi dalam etanol dengan menggunakan spektrofotometer UV-Vis memberikan satu puncak serapan. Spektrum spektrofotometer UV-Vis dari fraksi ditunjukkan pada Gambar 2.

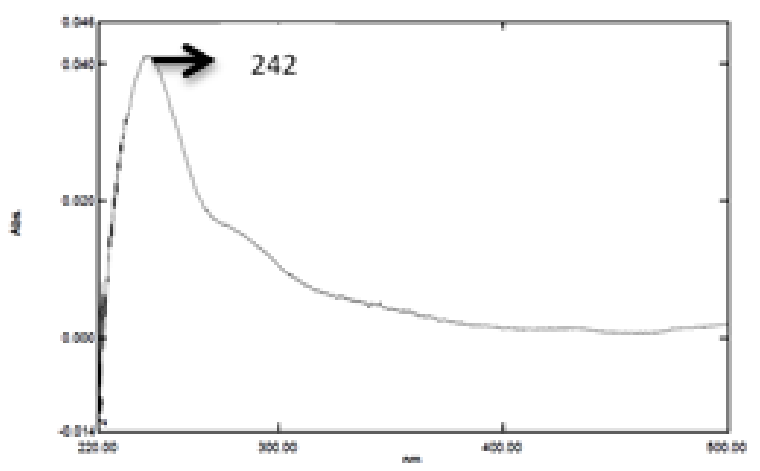

Gambar 2. Spektrum UV-Vis Fraksi A 
Dari hasil spektrum pada Gambar 2, menunjukkan serapan maksimum pada panjang gelombang $242 \mathrm{~nm}$ dengan absorbansi 0,041. Penelitian Rita (2010) terhadap Rimpang Temu Putih (Curcuma zedoaria (Berg.) Roscoe) juga menunjukkan serapan maksimum yang sama dan diduga diakibatkan oleh adanya transisi elektron dari $n-\sigma^{*}$ yang disebabkan oleh adanya suatu kromofor $\mathrm{C}=0$. Selain itu, serapan maksimum 242 $\mathrm{nm}$ juga terdapat pada penelitian Syahbirin et al. (2012) yang menunjukkan bahwa transisi yang mungkin terjadi adalah dari $\Pi^{-} \Pi^{*}$ atau $n-\sigma^{*}$. Transisi ini adalah untuk senyawa dengan ikatan rangkap berkonjugasi dan dihasilkan oleh kromofor $-\mathrm{C}=\mathrm{C}$ aromatik, $-\mathrm{C}=\mathrm{O},-\mathrm{C}-\mathrm{O},-\mathrm{NH}, \mathrm{NH}_{2}$, dan $-\mathrm{NHR}$. Hal ini didukung dari hasil analisis spektrofotometri inframerah yang menunjukkan fraksi mempunyai gugus fungsi $\mathrm{C}=0$ pada daerah bilangan gelombang1603,88 $\mathrm{cm}^{-1}$. Menurut Silverstein \& Webster (1986), gugus kromofor $\mathrm{C}=0$ merupakan gugus yang menyerap radiasi pada daerah ultraviolet yaitu diantara $200-400 \mathrm{~nm}$. Berdasarkan dari hasil analisis data IR dan UV-Vis dapat diduga bahwa hasil isolasi dari ekstrak etanol tepung pelepah batang aren meruapakan senyawa yang tersubtitusi gugus $-\mathrm{C}=\mathrm{O},-\mathrm{C}-\mathrm{O}$ ester, $-\mathrm{C}=\mathrm{C}$ alkena, serta $\mathrm{C}-\mathrm{C}$ dan $\mathrm{C}-\mathrm{H}$ alkana.

\section{Kesimpulan}

1. Dari hasil penelitian yang dilakukan menunjukkan bahwa fraksi yang diisolasi dari ekstrak etanol tepung pelepah batang aren bersifat toksik dengan nilai LC50 sebesar 269,15 ppm yang menunjukkan fraksi berpotensi sebagai pestisida.

2. Hasil karakterisasi senyawa toksik dari fraksi hasil isolasi ekstrak etanol tepung pelepah batang aren menggunakan spektrofotometer Inframerah dan UV-Vis merupakan senyawa nonpolar yang diduga mengandung gugus fungsi $-\mathrm{C}=\mathrm{O}$, $-\mathrm{C}-\mathrm{O}$ ester, $-\mathrm{C}=\mathrm{C}$ alkena, serta $\mathrm{C}-\mathrm{C}$ dan $\mathrm{C}-\mathrm{H}$ alkana.

\section{Daftar Pustaka}

Astuti, M.D., E.M. Kuntorini, \& F.E.P. Wisuda. 2014. Isolasi dan Identifikasi Terpenoid dari Fraksi nButanol Herba Lampasau (Diplazium esculentum Swartz). Valensi. 4(1): 20-24.

Mahmudah, M. 2014. Isolasi Dan Elusidasi Struktur Senyawa Metabolit Sekunder Ekstrak n-Heksana Daun Angiopteris palmiformis (Cav.) C.Chr serta Uji Toksisitas Akut dengan Metode Brine Shrimp Lethality Test (BSLT) [skripsi]. FKIK UIN, Jakarta.
McLaughlin, J.L., C.J. Chang, dan D.L. Smith. 1991. Bench-Top, Bioassay for The Discovery of Bioactive Naturals Products, An Update, Natural Product Chemistry. Elseiveir, Amsterdam.

Meyer, B. N., N. R. Ferrigni, J. E. Putnam, L. B. Jacobsen, D. E. Nichols \& J. L. McLaughlin. 1982. Brine Shrimp: A Covenient General Bioassay for Active Plant Constituens. Planta Medica. 45:31-34.

Mokoginta, N. F. 2014. Aktivitas Antioksidan Ekstrak Pelepah Pohon Aren (Arenga pinnata Merr.) [skripsi]. FMIPA ITB, Bogor.

Ridhia, S. Ibrahim, \& M. Efdi. 2013. Isolasi dan Karakterisasi Triterpenoid dari Fraksi n-Heksan pada Kulit Batang Srikaya (Annona squamosa L.). Jurnal Kimia Unand. 2(1):83-86.

Rita, W.S. 2010. Isolasi, Indentifikasi, dan Uji Aktivitas Antibakteri Senyawa Golongan Triterpenoid pada Rimpang Temu Putih (Curcuma zedoaria (Breg.) Roscoe). Jurnal Kimia. 4(1):20-26.

Roberts, J.D. 1977. Basic Pronciples of Organic Chemistry Second Edition. W.A Benjamin, Inc, California.

Rumondang, M., D. Kusrini, \& E. Fachriyah. 2013. Isolasi, Identifikasi dan Uji Antibakteri Senyawa Triterpenoid dari Ekstrak n-Heksana Daun Tempuyung (Sonchus arvensis L.). Chemistry Informasi. 1(1):156-164.

Sangi, M., L. Momuat \& M. Kumaunang. 2012. Uji Toksisitas dan Skrining Fitokimia Tepung Gabah Pelepah Aren (Arenga pinnata). Jurnal IImiah Sains. 12(2):128-134.

Sastrohamidjojo, H .1997. Spektroskopi. Liberty, Yogyakarta.

Silva, G.L., I.S. Lee, \& A.D. Kinghom. 1998. Special Problem with Extraction of Plants in Chanell R.JP. (ed) Methods in Biotechnology 4. Natural Product Isolation Human Press, Totowa, New Jersey, USA.

Silverstein, R.M., \& F.X. Webster. 1996. Spectromotric Identificartion of Organic Compounds. State University of New York, New York.

Smith, J. G. 2006. Organic Chemistry. McGraw-Hill Companies, Inc, New York.

Syahbirin, G., I. Batubara, T. Setiawati \& L. Nulhakim. 2012. Senyawa Aktif Daun Picung (Pangium edule Reinw) Sebagai Insektisida Botani terhadap Ulat Grayak (Spodoptera litura F.) (Lepidoptera: Noctuidae). Prosiding Simposium Nasional Kimia Bahan Alam XV. HIm. 56-66. 